\title{
Postpartum depression symptoms in survey-based research: a structural equation analysis
}

Che Wan Jasimah Bt Wan Mohamed Radzi, Hashem Salarzadeh Jenatabadi ${ }^{* \dagger}$ and Nadia Samsudin ${ }^{\dagger}$

\begin{abstract}
Background: Since the last decade, postpartum depression (PPD) has been recognized as a significant public health problem, and several factors have been linked to PPD. Mothers at risk are rarely undetected and underdiagnosed. Our study aims to determine the factors leading to symptoms of depression using Structural Equation Modeling (SEM) analysis. In this research, we introduced a new framework for postpartum depression modeling for women.
\end{abstract}

Methods: We structured the model of this research to take into consideration the Malaysian culture in particular. A total of 387 postpartum women have completed the questionnaire. The symptoms of postpartum depression were examined using the Edinburgh Postnatal Depression Scale (EPDS), and they act as a dependent variable in this research model.

Results: Four hundred fifty mothers were invited to participate in this research. $86 \%$ of the total distributed questionnaire received feedback. The majority of $79.6 \%$ of respondents were having depression symptoms. The highest coefficients of factor loading analysis obtained in every latent variable indicator were income $(\beta=0.77)$, screen time $(\beta=0.83)$, chips ( $\beta=0.85$ ), and anxiety $(\beta=0.88$ ). Lifestyle, unhealthy food, and BMI variables were directly affected by the dependent variable. Based on the output, respondents with a high level of depression symptoms tended to consume more unhealthy food and had a high level of body mass indexes (BMI). The highest significant impact on depression level among postpartum women was unhealthy food consumption. Based on our model, the findings indicated that $76 \%$ of the variances stemmed from a variety of factors: socio-demographics, lifestyle, healthy food, unhealthy food, and BMI. The strength of the exogenous and endogenous variables in this research framework is strong.

Conclusion: The prevalence of postpartum women with depression symptoms in this study is considerably high. It is, therefore, imperative that postpartum women seek medical help to prevent postpartum depressive symptoms from worsening.

Keywords: Postpartum depression symptoms, Structural equation modeling, Obesity, Edinburgh postnatal depression scale

\footnotetext{
* Correspondence: jenatabadi@um.edu.my

${ }^{\dagger}$ Hashem Salarzadeh Jenatabadi and Nadia Samsudin contributed equally to this work.

Department of Science and Technology Studies, Faculty of Science,

University of Malaya, 50603 Kuala Lumpur, Malaysia
}

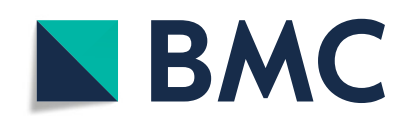

(c) The Author(s). 2021 Open Access This article is licensed under a Creative Commons Attribution 4.0 International License, which permits use, sharing, adaptation, distribution and reproduction in any medium or format, as long as you give appropriate credit to the original author(s) and the source, provide a link to the Creative Commons licence, and indicate if changes were made. The images or other third party material in this article are included in the article's Creative Commons licence, unless indicated otherwise in a credit line to the material. If material is not included in the article's Creative Commons licence and your intended use is not permitted by statutory regulation or exceeds the permitted use, you will need to obtain permission directly from the copyright holder. To view a copy of this licence, visit http://creativecommons.org/licenses/by/4.0/ The Creative Commons Public Domain Dedication waiver (http://creativecommons.org/publicdomain/zero/1.0/) applies to the data made available in this article, unless otherwise stated in a credit line to the data. 


\section{Background}

The number of people diagnosed with depression has been steadily increasing over the years. It affects the patient's work performance, financial status, and interpersonal relationships [1]. Depression can be observed from the individual's passive behavior such as loss of interest, feelings of guilt, low self-respect, sleep-deprived, poor appetite, constantly being unhappy, or showing signs of fatigue [2, 3]. Living with depression causes a serious disability to the patient because it is associated with mental and behavioral disorders [4]. It is highly probable that this condition affects the patient's physical wellbeing leading to increased morbidity and mortality $[1,5$, 6]. In 2017, the World Health Organization (WHO) reported that over 300 million people suffered from depression [7]. However, previous studies showed that depression typically occurred among women, as opposed to men [8]. The primary reasons for depression among women were attributed to hormonal transition, such as puberty, pregnancy, and menopausal changes [1]. In particular, after giving birth, a woman needs extra care and should be given the right kind of health care priorities. Moreover, any unpleasant act can cause depression at this stage which will be devastating for the whole family [9]. Postpartum depression (PPD) was identified as the number one complication that plagued one in seven women [10]. It has been estimated that more than $20 \%$ of women globally suffer from PPD [11]. PPD usually occurs 6 to 8 weeks after childbirth, which may lead to a decrease in an individual's daily performance [12]. Mothers are commonly faced with discomfort due to physical changes, poor sleeping quality, and various uncertainties related to their newborns in the postpartum stage [13].

Today, PPD has become a major worldwide health problem. Even so, many women with this mental illness were not medically diagnosed [12]. Several factors associated with PPD have been identified, although the specific causes remained unknown [11]. Previous studies have shown that depression and obesity were closely linked [14, 15]. The risk of depression was increased by almost $37 \%$ due to obesity among women. It is quite common among women to gain excessive weight during pregnancy and the postpartum period [16]. Ertel et al. [17] and LaCoursiere et al. [18] also claimed that there was some evidence regarding pre-pregnancy obesity, which may lead to PPD. This claim was also supported by similar research conducted by Ruyak et al. [19]. Mgonja and Schoening [10] and Ezzeddin et al. [20] further placed emphasis on the issue by examining factors, aside from obesity, that could lead to the development of PPD; the factor included poor marital relationships, divorce, substance abuse, violence, other mental health diagnoses, low educational levels, unwanted or unexpected pregnancies, complicated labor, and a weak health care support system. This assertion by Mgonja and Schoening were reinforced by similar findings by Azale et al. [21], Zhao et al. [22], and Ukatu, Clare, and Brulja [11] who focused on factors leading to maternal depression. Hence, Bledsoe et al. [23] concluded that the negative outcomes from social, educational, health, and economic aspects tend to contribute a high possibility for the development of PPD among women. There is significant evidence that genetics and biochemical factors (brain chemistry), personality style, illness, and significant transitions in life, including adjusting to living with a new baby, may also contribute to PPD [24, 25]. Postpartum depression has also been linked to women's lifestyle choices, such as sleep quality [26], exercise [27], and prenatal smoking [28]. Dos Santos et al. [29] concluded that women who were diagnosed with maternal depression also experienced a higher risk of eating disorders during their pregnancies. Unhealthy eating habits developed among pregnant women because they were afraid to gain weight whenever they ate. Nevertheless, pregnant women with an eating disorder could have healthier food options, and some were concerned with their body shape rather than their body weight [30]. In other words, body dissatisfaction seemed to be a predictor of weight gain during pregnancy due to lifestyle factors (e.g., physical activity, diet, stress, and fatigue levels) [31]. In essence, a mother needs to have healthy food in order to supply the right kinds of nutrition to her unborn child [32].

Unfortunately, there were very few studies that investigated the impact of lifestyle and food intake by considering the body mass index (BMI), which may be associated with the PPD occurrence among women. Previous studies on PPD were infrequent; some utilized a modeling technique to measure the output and estimated the suggested indicators. Despite the contribution of these variables to PPD, a combined analysis of indicators involved in postpartum depression is surprisingly non-existent. A Structural Equation Modelling (SEM) analysis would allow the integration of variables such as demographic, lifestyle, and food intake in a conceptual model, which interrelates each of these variables to PPD. Therefore, in this research work, the authors aimed to analyze the factors, which contribute to PPD, and its relationship with socio-demographics, the lifestyle of postpartum women, healthy food intake, unhealthy food intake, and BMI range, which affects PPD by using SEM analysis.

\section{Methods}

\section{Research framework}

The authors designed a research framework that correlated to PPD, as shown in Fig. 1. The conceptual framework of the research model includes an integrated model capable of providing an inclusive evaluation of the latent and observed variables within the SEM 


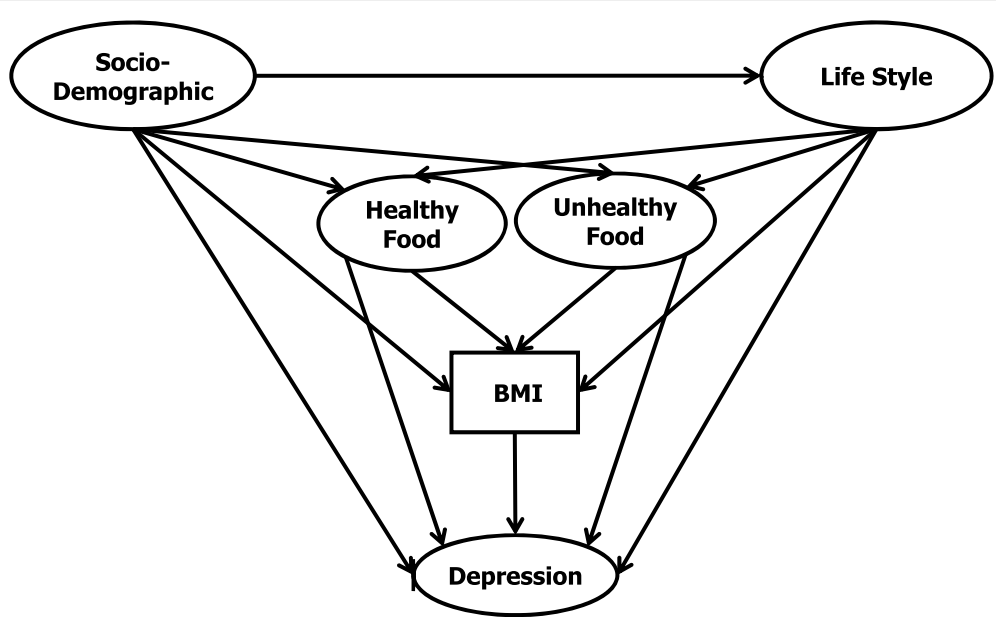

Fig. 1 Research framework

framework. The framework comprises socio-demographics as the initial independent variable and the depression level as the dependent variable. The remaining variables which acted as mediators were lifestyle, healthy food, unhealthy food, and BMI. As the BMI needed to be calculated based on the respondent's weight and height, it was the only measured variable in our research framework. These variables have been taken into consideration the Malaysian culture because Malaysia is a multiracial country and have various ethnic groups [33]. Thus, we had chosen the variables wisely which were practical among Malaysian mothers.

The research framework provides a clear view of the study is carried out. By constructing the framework, it will lead this research to achieve its objective. This research framework was constructed using a combination of a theoretical framework with the addition of some new ideas to analyze the model. According to previous studies, socio-demographic variables played a significant role in establishing the relationship between the variables to postpartum women. These variables include with their lifestyles [34], healthy food intake [35], unhealthy food intake [36], BMI [37], and depression [38]. Lifestyle intervention during the postpartum period that give an impact on healthy food and unhealthy food intake [39], BMI [40], and depression [41] had also been investigated by other researchers.

Apart from that, food consumption among postpartum women has an interrelationship with BMI that claimed by research conducted by Kay et al. [42]. It was reported by Nathanson et al. [35] that healthy food intake closely associated with depression. Yet, Faria-Schutzer et al. [43] claimed that unhealthy food intake correlated with depression. Based on Ertel et al.'s [17] research, the postpartum BMI level can be affected by the depression level.

\section{Materials and measurements}

In this research, socio-demographics were measured as the initial independent variable, which includes four indicators, i.e., age group, educational background, working experience, and income household per month. The age range was classified into four groups: 21 to 25 years old, 26 to 30 years old, 31 to 35 years old, and over 35 years old. The educational background of the respondents was categorized as "Less than high school", "High school", "Diploma", "Bachelor's degree" and "Master's degree or Ph.D.". The respondents were asked about their working experience, which was categorized as "no job experience", " 1 to 3 years", " 4 to 6 years", " 7 to 10 years", and "more than 10 years". The last question in the sociodemographic section was based on to the monthly household income in Ringgit Malaysia (RM) and the responses were classified as "Less than RM 2,000", "RM 2,000-RM 3, 000", "More than RM 3,000 to RM 4,000", "More than RM 4,000 to RM 5,000", and "Over RM 5,000".

Apart from that,the authors measured lifestyle based on Nakayama, Yamaguchi's study [44] in which the authors selected a few indicators such as the average working hours per day, physical activity per week, and average sleeping hours per day. Besides, daily screen time (e.g., $\mathrm{TV}$, smartphone, tablet, etc.) was added to measure the lifestyle of the respondents in terms of social media, which corresponded to Khajeheian et al.'s research [45]. Regarding the average working hours per day, the responses consisted of five categories denoted by "none", "less than 7 hours", "7 to 8 hours", "8 to 9 hours" and "more than 9 hours". As for the frequency of physical activity per week, this was indicated as "none", "1 time", " 2 times", " 3 times", " 4 times", and "more than 4 times". The average screen time per day was denoted as "less than 1 hour", "1 to 2 hours", "2 to 3 hours", " 3 to 4 hours", and "more than 4 hours". The average sleeping hours per day were indicated 
as "less than 6 hours", " 6 to 7 hours", " 7 to 8 h", " 8 to 9 h", and "more than $9 \mathrm{~h}$ ".

In addition to the mediators, the authors considered healthy and unhealthy food separately in this study. Fruits, vegetables, and whole grains were selected as 'healthy food' variables, whilst fast food such as sweets, chips, and soft drinks was categorized as 'unhealthy food' [42, 46]. The respondents were asked about their healthy and unhealthy food intake, and the responses were based on a five-point scale ("never", "rarely", "sometimes", "mostly", and "always") which have been used in the previous studies [47].

WHO defined BMI as a simple index of weight-toheight of an individual and calculated according to the formula, $\mathrm{BMI}=(($ weight in kilograms $) /$ (height in meters $)^{2}$ ) [48]. There are four categories of BMI based on the BMI range including "underweight for less than 18.5 $\mathrm{kg} / \mathrm{m}^{2}$ ", "normal for ranges between 18.5 to less than $25.0 \mathrm{~kg} / \mathrm{m}^{2}$ ", "overweight for ranges between $25.0 \mathrm{~kg} / \mathrm{m}^{2}$ to less than $30.0 \mathrm{~kg} / \mathrm{m}^{2}$ " and "obese for ranges between $30.0 \mathrm{~kg} / \mathrm{m}^{2}$ and above" [49].

For the dependent variable, the authors measured the depressive symptoms using the Edinburgh Postnatal Depression Scale (EPDS) questionnaire to validate prenatal and postpartum occurrences [50-53]. Moreover, previous studies have shown that EPDS had been validated in Malaysian samples as well [54, 55]. EPDS was calculated using a four-point scale (0-4) for each item to measure the frequency of the depressive symptoms developed in the postpartum period. A total of 10 items was used in the EPDS to estimate the depressive symptoms of respondents that needed to be answered. The total score for the EPDS questions was then grouped into four categories with a different interpretation. A 0-9 score was categorized as "normal", scores of 10-11 were categorized as "slightly increased risk", scores of 12 to 15 as "increased risk" and those more than 15 were listed as "likely depression" [56].

\section{Structural equation modeling (SEM)}

The SEM technique was chosen to be used in this research as it was recognized as a suitable method that would most likely help a researcher to understand better the latent variables concepts and the interactions within the model. Several previous studies had used the structural equation methodology $[57,58]$ in their studies due to its features. The features of SEM technique include being:

- Capable of estimating and examining the direct and indirect interrelationships which exist among the variables in the research study [59].

- Capable of showing the relationship among dependent variables, which helps indicate the simultaneous estimation of more than one exogenous and endogenous variable [60].

\section{Sampling}

For sampling, we used a cross-sectional analysis. The survey data was collected from each subject at one point in time. Based on Hair et al. [61], the required sample size depended on the number of latent variables in the study, including the number of indicators. In other words, a) 100 respondents were needed due to five or less latent variables, of which each of the latent variables included at least three indicators, b) 150 respondents were needed due to seven or less latent variables, of which each of the latent variables included at least three indicators, c) 300 respondents were needed since seven or less latent variables existed, of which some of the latent variables had less than three indicators, d) 500 respondents were needed due to the existence of more than seven latent variables, of which some of the latent variables had less than three indicators. In this research framework, the authors had five latent variables, to be precise. Thus, the authors were required to consider at least 150 respondents for a suitable sample size.

The respondents were selected randomly using proportionate stratified random sampling and the data were collected for almost 6 months. The questionnaires were selfadministered and have been distributed online, by sending respondents the link. However, for respondents who don't have access to the internet, they were given the printed questionnaire to fill up. The authors distributed 450 questionnaires to postpartum women who were living in Kuala Lumpur, the most highly populated city in Malaysia. We excluded the women who are not living in Kuala Lumpur from the analysis. A total of 387 completed questionnaires were received from the respondents. The data were collected from nine maternal and child health clinics around Kuala Lumpur. The maternal and child health clinics that we went for data collection were in the neighborhood area which most of the patients are living nearby the clinics. We chose to collect the data at the maternal and child health clinics because it was easy to recognize mothers in their one-year postpartum period as mothers went to the clinics for medical check-ups. The respondents were selected randomly as long as they met the main criteria, i.e., in the first postpartum year of their latest pregnancy. The survey was conducted under the backingsof the University of Malaya's Research Ethics Committee approval (UM.TNC2/RC/H\&E/UMREC 127) and with the grant obtained from the University of Malaya (Grant No.: GPF066B-2018andGC002C-17HNE).

\section{Results}

Table 1 shows the descriptive statistics of this research. The respondents are made up of Malays (43.7\%), Chinese (34.9\%), and Indians (21.4\%), who were mostly around 31 years of age and older. The majority of participants were educated and gained an income of over RM 
Table 1 Descriptive statistics

$$
\begin{aligned}
& \text { Number Percentage } \\
& \text { BMI }\left(\mathrm{kg} / \mathrm{m}^{2}\right) \\
& \text { Underweight }(\mathrm{n}, \%) \\
& \text { Normal }(\mathrm{n}, \%) \\
& \text { Overweight }(\mathrm{n}, \%) \\
& \text { Obese }(\mathrm{n}, \%) \\
& \text { Age }(\mathrm{n}, \%) \\
& 21 \text { to } 25 \text { years old } \\
& 26 \text { to } 30 \text { years old } \\
& 31 \text { to } 35 \text { years old } \\
& \text { Over } 35 \text { years old }
\end{aligned}
$$

Education ( $\mathrm{n}, \%)$

Less than high school
High school
Diploma
Bachelor
Master or PhD

Income $(n, \%)$

Less than RM 2000

RM 2000-RM 3000

More than RM 3000- RM 4000

More than RM 4000- RM 5000

Over RM 5000

\section{Job Experience $(n, \%)$}

No job experienced

1-3 years

4-6 years

7-10 years

More than 10 years

Physical Activity (n, \%)

None
1 time
2 times
3 times
4 times
More than 4 times

Screen Time $(n, \%)$

$$
\begin{aligned}
& \text { Less than } 1 \mathrm{~h} \\
& 1-2 \mathrm{~h} \\
& 2-3 \mathrm{~h} \\
& 3-4 \mathrm{~h}
\end{aligned}
$$

More than $4 \mathrm{~h}$

Sleeping $(n, \%)$

Less than $6 \mathrm{~h}$

$$
\text { 6-7h }
$$

Table 1 Descriptive statistics (Continued)

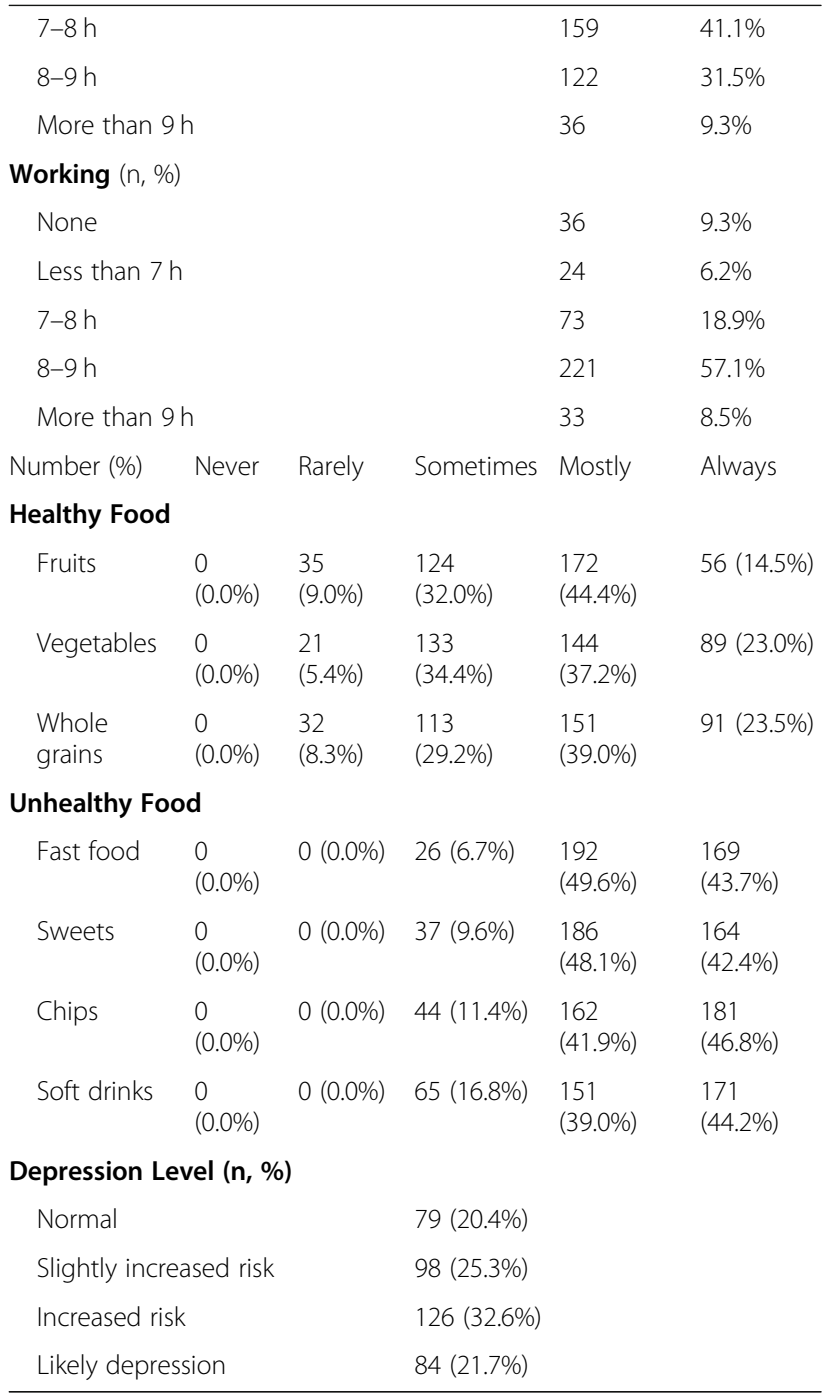

3000 per month with 1 to 10 years of working experience. Based on the weight and height provided by the respondents, $38.0 \%$ of participants were obese, $28.7 \%$ were overweight, $24.8 \%$ were normal, and $8.5 \%$ were underweight. Regarding lifestyle, only $26.1 \%$ of respondents did not take part in any physical activities. The average sleeping hours of the respondents were around 7 to $9 \mathrm{~h}$, coupled with 8 to $9 \mathrm{~h}$ working day. The mean screen time hours recorded were 4.08 (SD: $0.85 \mathrm{~h}$ ) per day. In terms of the food intake among postpartum women, the majority of respondents mostly consumed fruits, vegetables, whole grains, fast food, and sweets. Apart from that, a large number of respondents always consumed chips and soft drinks. Based on the calculated EPDS score, only $20.4 \%$ of the respondents were normal. Depression levels for the rest of respondents were 25.3\% (slightly increased risk), $32.6 \%$ (increased risk), and 21.7\% (likely depression). 
Fornell and Larcker [62] claimed that the validity and reliability of a survey needed to fit the requirements of the SEM analysis. The validity is supposed to be tested based on the Cronbach's alpha coefficient. Every latent variable in the research framework should be equal to or higher than 0.7. The Cronbach's alpha value in this research was more than 0.7 , which aligned with the conditions required to validate this research. To examine the reliability of the research work, a loading factor higher than 0.7 needed to be obtained for the latent variable indicator (see Table 2). In Table 2, several indicators obtain a factor loading coefficient of less than 0.7 , which means that these indicators need to be eliminated from the SEM analysis.

The reliability of the research also needed to be fitted with another test after the elimination of these unfit

Table 2 Factor loading analysis

\begin{tabular}{|c|c|}
\hline \multicolumn{2}{|l|}{ Socio-demographics } \\
\hline $\operatorname{Age}^{a}$ & 0.63 \\
\hline Education & 0.73 \\
\hline Income & 0.77 \\
\hline Job Experience & 0.72 \\
\hline \multicolumn{2}{|l|}{ Lifestyle } \\
\hline Physical Activity & 0.74 \\
\hline Screen Time & 0.83 \\
\hline Sleeping & 0.72 \\
\hline Working & 0.79 \\
\hline \multicolumn{2}{|l|}{ Healthy and Unhealthy food } \\
\hline Fruits $^{a}$ & 0.65 \\
\hline Vegetables & 0.76 \\
\hline Whole grains & 0.81 \\
\hline Fast food & 0.73 \\
\hline Sweet & 0.76 \\
\hline Chips & 0.85 \\
\hline Soft drinks & 0.83 \\
\hline \multicolumn{2}{|l|}{ Depression } \\
\hline I have been able to laugh and see the funny side of things (Q1) & 0.72 \\
\hline I have looked forward with enjoyment to things (Q2) & 0.76 \\
\hline $\begin{array}{l}\text { I have blamed myself unnecessarily when things went wrong } \\
\text { (Q3) }{ }^{a}\end{array}$ & 0.62 \\
\hline I have been anxious or worried for no good reason (Q4) & 0.88 \\
\hline I have felt scared or panicky for no very good reason (Q5) ${ }^{a}$ & 0.54 \\
\hline Things have been getting on top of me (Q6) & 0.81 \\
\hline I have been so unhappy that I have had difficulty sleeping (Q7) & 0.73 \\
\hline I have felt sad or miserable $(\mathrm{Q} 8)^{a}$ & 0.68 \\
\hline I have been so unhappy that I have been crying (Q9) & 0.79 \\
\hline The thought of harming myself has occurred to me (Q10) & 0.74 \\
\hline
\end{tabular}

indicators. All latent variables should obtain an equal or higher coefficient than 0.5 of the average variances extracted (AVE). AVE analysis for latent variables in this research achieved more than 0.5. Thus, in this research work, the validity and reliability features are fulfilled. The suitability of the research model was tested using the model fitting analysis. The comparative fit index (CFI), normed fit index (NFI), relative fit index (RFI), incremental fit index (IFI), the goodness of fit index (GFI), and Tucker-Lewis index (TLI) coefficient of this research were above 0.9, which means that the research data was acceptable. The structural model in the SEM analysis helped to recognize the connection between research variables and the considered conceptual model. Figure 2 shows the output of the structural model for postpartum women. From the pre-established 14 relationships between the research variables, only five relationships, represented by the dashed black arrow, were deemed not significant.

Figure 2 presents that $\mathrm{R}$-square is equal to 0.76 . which means that $76 \%$ of depression variations depend on BMI, healthy food intake, unhealthy food intake, lifestyle, and socio-demographics among postpartum women. The rest, $24 \%$ of depression variation belongs to other variables that were not involved inside the model. Moreover, from 14 relationships among research variables, nine of them have significant relationships. Among the four latent variables and one measurement variable, two of the latent variables i.e. unhealthy food and lifestyle, have a significant relationship with depression. Additionally, BMI as the only measurement variable has a significant relationship with depression. The highest relationships belong to unhealthy food intake $\rightarrow$ depression (0.84), lifestyle $\rightarrow$ depression (0.81), and BMI $\rightarrow$ depression (0.79). Socio-demographics, as the main independent variable has a significant relationship with healthy and unhealthy food intakes and there is no significant relationship with the lifestyle, BMI, and depression. However, socio-demographics has an indirect effect on depression through food intake mediators (socio-demographics $\rightarrow$ unhealthy food intake $\rightarrow$ BMI $\rightarrow$ depression) and (socio-demographics $\rightarrow$ unhealthy food intake $\rightarrow$ BMI $\rightarrow$ depression). As a result, sociodemographics has no direct effect on depression but have an indirect significant effect. Besides, sociodemographics also do not have a significant direct effect on BMI. It means that postpartum women with any spectrum of socio-demographics including age, education, income, and job experience has no significant effect on their BMI and depression. The correlation of these indicators as a latent variable indicates that their BMI and depression will be significantly affected through their food intake. Meanwhile, Table 3 presents the $p$-value of the final output obtained was significant (approximately $p$-value $<0.05$ ). 


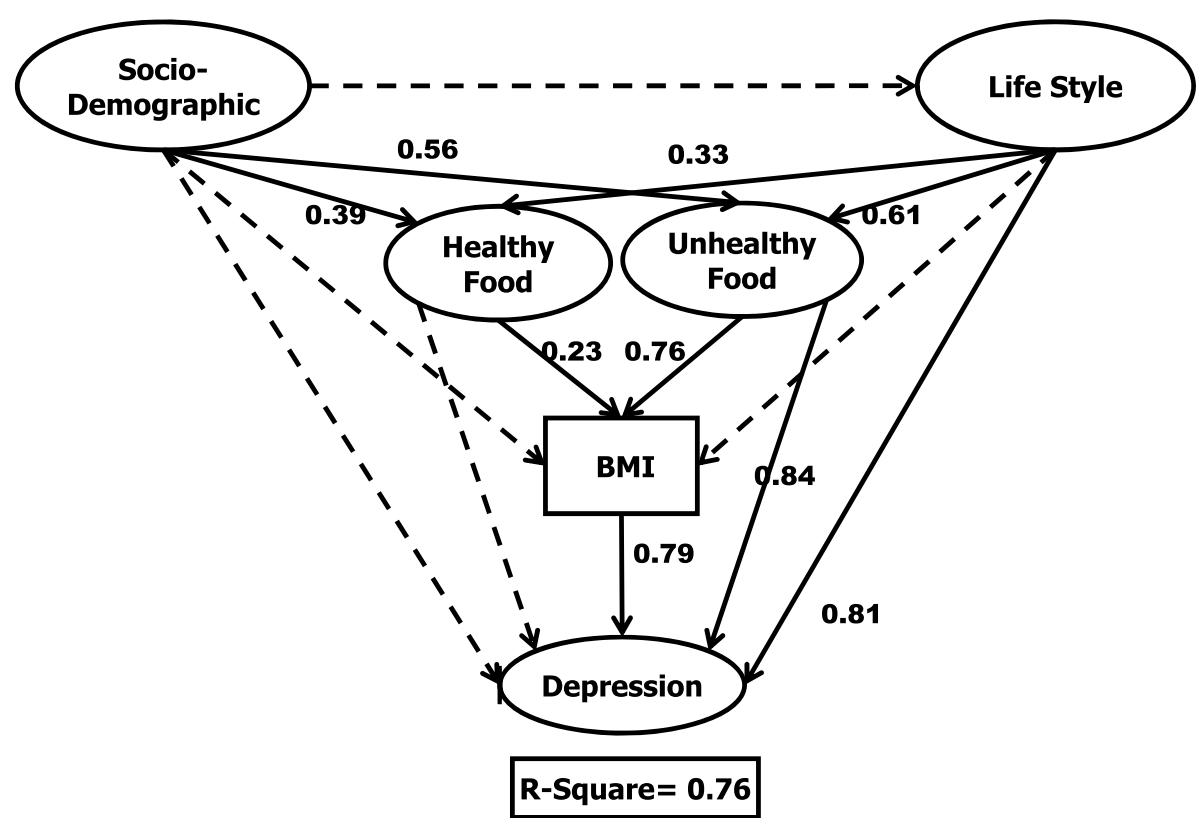

Fig. 2 Final output of structural model

\section{Discussion}

This paper aimed to introduce a new postpartum depression model, which is designed based on factors associated with depression symptoms using the SEM technique. The depression levels of postpartum women were set as the dependent variable, and sociodemographics were maintained as an independent variable. In this research framework, lifestyle, healthy food, unhealthy food, and BMI acted as mediators. Based on previous theories and frameworks of postpartum depression, the authors designed an improved study model, as shown in Fig. 1. The authors succeeded in gathering the questionnaires from 387 women diagnosed with postpartum. The respondents were into their first postnatal year, which matched the previous research conducted by Kubota et al. [51].

Table $3 P$-value output

\begin{tabular}{ll}
\hline Relationships between variables & Significant \\
\hline Socio-demographics $\rightarrow$ Healthy food & $<0.0104$ \\
Socio-demographics $\rightarrow$ Unhealthy food & $<0.0094$ \\
Lifestyle $\rightarrow$ Healthy food & $<0.0177$ \\
Lifestyle $\rightarrow$ Unhealthy food & $<0.0069$ \\
Lifestyle $\rightarrow$ Depression & $<0.0010$ \\
Healthy food $\rightarrow$ BMl & $<0.0241$ \\
Unhealthy food $\rightarrow$ BMl & $<0.0010$ \\
Unhealthy food $\rightarrow$ Depression & $<0.0010$ \\
BMl $\rightarrow$ Depression & $<0.0010$ \\
\hline
\end{tabular}

For this research model, 14 out of nine relationships among the variables were significant, with a positive coefficient. In Fig. 2, we simplified our research model output. Thus, the significant impact of socio-demographics on healthy and unhealthy food is 0.39 and 0.56 , respectively. It can be interpreted that respondents who have more money, good education backgrounds, and longer work experience tend to consume more unhealthy food than healthy food. Previous research [63] has reported that working mothers tend to feed the family with fast-food as it is the easiest and fastest way to prepare the meal. Yet, some research also mentioned that working mothers had bettereating practices [64]. These show a very contradictory output from the prior studies. On the other hand, it is claimed by Zagorsky and Smith [65] that adults from different levels of socio-demographicspreferred to consume fast food. This claim is supported by similar research done by Fryar, Hughes, Herrick, Ahluwalia [66]. Good educational background was linked with a greater frequency of fast food consumption among women as well [67]. In this research, we obtained a result showing that a high level of socio-demographics chose to eat unhealthy food more. It is proven before that the rationale for people consuming fast food due to convenience and wanted to socialize [68].

The age group indicator was eliminated from the SEM analysis, as the coefficient of factor loading did not achieve the required standard value. Additionally, the lifestyle variable is significant in terms of affecting the dependent variable in this research model. Referring to the factor loading analysis in Table 2, the lifestyle indicators show that the average screen time 
hour has the highest loading factor, followed by the average working hour indicator. Previous studies have shown a positive correlation between smartphone addiction and depression [69]. The lifestyle factor had a significant impact on both food intake categories. An increase in terms of lifestyle will promote an increase in depression levels and food consumption, in particular, unhealthy food. Berk et al. [70] summarized that poor lifestyle and unhealthy diet contributed to depression.

Apart from that, healthy and unhealthy foods show a significant correlation with BMI in the structural model. In previous studies, it was reported that food consumption contributed to the BMI range [70, 71]. To be exact, the quantity of the food that we consumed affected the BMI level. This will occur when you are eating healthy food but in a substantial amount, which will consequently lead to an increase in the BMI level. So, to apply healthy eating behavior, it is better to know the number of calories needed for the individual's body. Based on the factor loading analysis in Table 2, the chips indicator had the highest coefficient among the indicators of other food categories. Previous studies also claimed that snacks (i.e., chips) have an impact on the BMI of postpartum women [71]. When a comparison was made between the food categories' impact on BMI, unhealthy food has a higher significant coefficient than healthy food. Therefore, an increase in unhealthy food intake will also increase the BMI levels of respondents. In Malaysia, unhealthy foods are easy to find and mostly cheaper than healthy food. As in Kuala Lumpur, a lot of 24-h restaurants are available, especially fast-food premises [72]. Thus, with the availability of easy food at any hours, people with high socio-economic backgrounds sometimes do choose to eat unhealthy food too. Even though people are well aware of the effect of eating unhealthy foods, it depends on an individual on what they choose to consume.

Based on Fig. 2, unhealthy food and BMI have a significant impact on the depression levels, which seem to directly affect the dependent variables. The prevalence of overweight and obesity among postpartum women in the research sample is noted to be among the highest. From this research, the respondents who eat more unhealthy food and has a high level of BMI are considered to have a high level of depression. Several studies have claimed that depression has a link with maternal obesity $[73,74]$. Body dissatisfaction in terms of image, shape, or weight among women would probably affect their mental health.

In the EPDS section, the 10-item questions included anhedonia, self-blame, anxiety, fear or panic, inability to cope, sleeping difficulty, sadness, tearfulness, and self- harm ideas [75]. The descriptive output found that the majority of the respondents suffered from an increased risk of depression levels. The result of depression levels among mothers indeed raised concerns, where they needed help but did not get any. However, in the factor loading analysis, there are three indicators of depression, that have been eliminated from the SEM analysis- Q3, Q5, Q8 (self-blame, fear or panic, and sadness, respectively). Although the descriptive statistics data consider the total score of the EPDS for all 10-items of the depression level measurement, it had decided to remove these indicators, as it had been included in the process of the postpartum depression modeling. The highest loading factor of depression item concerning the anxiety issue (Q4), and the lowest is the anhedonia issue (Q1). For these issues, this research would be an effective platform for medical professionals to keep updated and act towards postpartum women who might feel ashamed or afraid to seek help in preventing them from depression.

Physical activity intervention plays a part in weight loss which happens to be an alternative for the prevention and treatment of the depression symptoms [76]. Moreover, poor sleep incite less motivation to do exercise that leads to weight gain and also obesityrelated problemsas well as sleep disturbances [77]. Promotingphysical activity in an individual's lifestyle can also benefit in averting the potentialenhancement of chronic diseases for which body weight is a risk factor [76]. Consistent with previous literature [78], excessive weight gain probably happen alliance with low physical activity. When ones living with obesity or overweight, their engagement to workout is so frustrating due to discomfort complaints in terms of musculoskeletal and sweating [77]. Prior literature proves that physical activity was correlated with lower BMI and depression levels [79].

Based on Fig. 2, it is observed that the highest coefficient among the variables is the impact of unhealthy food on the depression levels. This corresponded with a previous study by Barker et al. [80], whereby the levels of depression symptoms were linked to unhealthy food consumption [81, 82]. Regarding the research model output, the indirect impact of unhealthy food on the depression levels with the BMI level was identified. Previous studies reported that people who were obese and depressed consumed more unhealthy food [83]. The R-square $\left(R^{2}\right)$ for the structural model in this research was 0.76 . In relative terms, $76 \%$ of the variations in depression level were related to socio-demographics, lifestyle, healthy food, unhealthy food, and BMI. Only $24 \%$ of the variations correlated with other factors. Thus, it can be concluded that the strength of exogenous and endogenous variables in this research is strong. 
However, this research had several limitations, as well. The respondent's weight and height were self-reported in this study, despite previous research works which have also utilized this method, and although it is valid [84-86], it can be a possible limitation of the study. Furthermore, physical activity that we measured was defined as regular exercise (e.g., fast walking, jogging, cycling, swimming), which were mentioned in the questionnaire. Being a mother had change women's lifestyle especially to engage in leisure-time especially physical activity [87]. Women seem to be a lack of doing any physical activity because of time constraints and managing their kids [88]. Mothers without husbands or partners were less physically active compared to married mothers [89]. Besides, some of them might work out in different places such as home, gym, park, etc. This indicator is not the main concern in this study. But it is a part of measuring how active the respondents were during the postpartum period.

While the dietary assessment was measured only by using a five-point Likert-type scale. Different BMI category needs different amounts of calories per day. As this research based on self-administrated questionnaires, the Likert-type scale seems to be the easiest way for respondents to report their dietary measurements. Not everyone knows how specific much of the food they consume every day. Yet, we believe that there a lot of ways to measure food intake. For example, the measurement would be in servings [90] or using the MooDFOOD dietary guidelines [91] which been used by recent studies.

Apart from that, the measurement of the depression levels using EPDS was not a substitute for a clinical diagnosis. EPDS was used in this research to determine depression symptoms, which the respondent might face as a form of risk. We acknowledge that many people who suffer from depression did not seek medical help [4]. Medical treatment programs for depression can be effective in reducing depression levels.
In this study, SEM with cross-sectional data could analyze the influence of lifestyle, healthy, and unhealthy food intake on depression. Nevertheless, our research framework, which was presented in Fig. 1, is not capable of studying the vice versa effect of depression on lifestyle, healthy and unhealthy food intake. To overcome this matter, we recommend future studies to apply dynamic SEM with longitudinal data. Figure 3 illustrates an example of dynamic SEM pertaining to our research framework.

The main framework of this study was prepared based on the combination of previous studies in obesity and depression model. However, calorie intake, genetics, and fiber intake are some of the variables that could be obesity indicators that might have been encompassed in our analysis. There were limitations to collect this type of data for this study, and it would have required a different research structure that could not be added in the current research framework. Hence, the analysis of these indicators in future studies is recommended.

\section{Conclusion}

To conclude, this research examined the effects of depression levels in terms of socio-demographics, lifestyle, healthy food, unhealthy food, and BMI. Besides, the hypothesized model in the present study had been indicated as a suitable model for predicting the depression levels among postpartum women. Subsequently, depression levels affect people's lives (e.g., personal matters, health, eating behavior), and it means clinical intervention is necessary to prevent depression symptoms from exacerbating. This research is the first study on postpartum women diagnosed with depression symptoms, which were carried out using SEM. The factors associated with depression were presented in the theoretical framework. The associated variables and theories were aligned with the Malaysian culture and the associated environment. Thereby, we believe that this research may be advantageous for future works on the postpartum depression modeling, particularly among public health and life science research scholars.

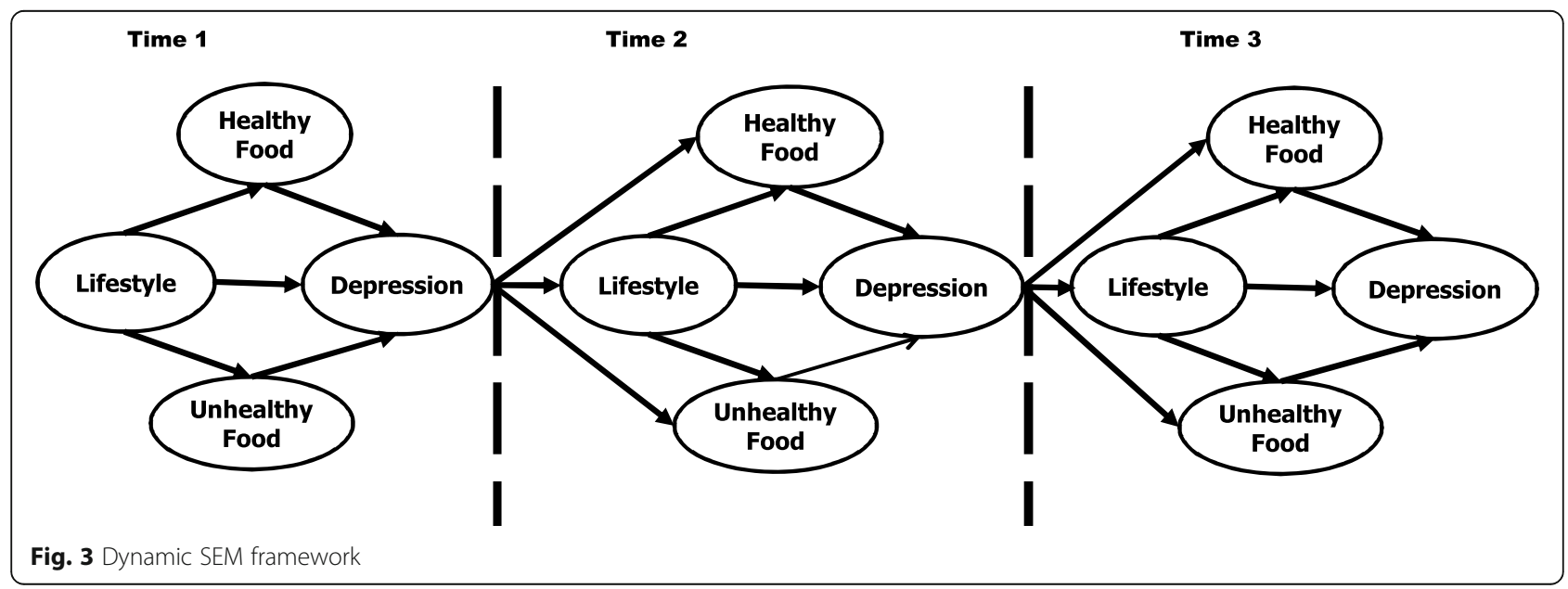




\section{Abbreviations}

PPD: Postpartum depression; SEM: Structural Equation Modeling; BMI: Body mass index (BMI); EPDS: Edinburgh Postnatal Depression Scale; R $^{2}$ R-square; RM: Ringgit Malaysia; CFI: Comparative fit index; NFI: Normed fit index; RFI: Relative fit index; IFI: Incremental fit index; GFI: Goodness of fit index; TLI: Tucker-Lewis index

\section{Acknowledgements}

The authors would like to express gratitude to all participants for their cooperation during the research.

\section{Authors' contributions}

Conceived of and designed the study: H.S.J and N.S. Performed the methodology: H.S.J and N.S. Analyzed and interpreted the data: H.S.J. Wrote the manuscript text: H.S.., C.W.J.W.M.R., and N.S. All authors reviewed the manuscript. All authors read and approved the final manuscript.

\section{Funding}

This research was supported by University of Malaya, Malaysia (Grant No: GPF066B-2018andGC002C-17HNE). The funders had no role in study design, data collection, and analysis, decision to publish or preparation of the manuscript. No additional external funding was received for this study.

\section{Availability of data and materials}

The data are not publicly available due to the University of Malaya Research Ethics Committee rules and regulations. The data that support the findings of this research are available upon reasonable request from the corresponding author and with permission of the University of Malaya Research Ethics Committee.

\section{Ethics approval and consent to participate}

The survey was conducted with the University of Malaya Research Ethics Committee approval (UM.TNC2/RC/H\&E/UMREC 127). The research methods were performed in accordance with the relevant guidelines and regulations. Participants of the study were informed about the purpose, objectives, and their right to participate, decline participation, or withdraw their participation in the research activities by verbal. Respondents have been notified that the information given was private and confidential which only going to use for academic purposes only. Written informed consent was obtained from all respondents.

\section{Consent for publication}

Not applicable.

\section{Competing interests}

The authors declare no competing interests.

\section{Received: 7 August 2019 Accepted: 1 December 2020}

Published online: 27 January 2021

\section{References}

1. Muharam R, Setiawan MW, Ikhsan M, Rizkinya HE, Sumapraja K. Depression and its link to other symptoms in menopausal transition. Middle East Fertility Society J. 2018;23(1):27-30.

2. El-Gilany AH, Elkhawaga GO, Sarraf BB. Depression and its associated factors among elderly: a community-based study in Egypt. Arch Gerontol Geriatr. 2018;77:103-7

3. Zeng N, Pope Z, Lee J, Gao Z. Virtual reality exercise for anxiety and depression: a preliminary review of current research in an emerging field. $J$ Clin Med. 2018;7(3):42

4. Archana PS, Das S, Philip S, Philip RR, Joseph J, Punnoose VP, et al. Prevalence of depression among middle aged women in the rural area of Kerala. Asian J Psychiatr. 2017;29:154-9.

5. Elamoshy R, Bird Y, Thorpe L, Moraros J. Risk of depression and suicidality among diabetic patients: a systematic review and meta-analysis. J Clin Med. 2018;7(11):445

6. Jia H, Zack MM, Gottesman II, Thompson W. Associations of smoking, physical inactivity, heavy drinking, and obesity with quality-adjusted life expectancy among US adults with depression. Value Health. 2018;21(3):364-71.

7. Organization WH. World Health Organization. https://www.who.int/mental health/management/depression/en/. Accessed 20 Dec 2018.
8. Jin QG, Mori E, Sakajo A. Risk factors, cross-cultural stressors and postpartum depression among immigrant Chinese women in Japan. Int J Nurs Pract. 2016:22:38-47

9. Correa MSM, Feliciano KVD, Pedrosa EN, de Souza Al. Postpartum follow-up of women's health. Cadernos De Saude Publica. 2017;33(3):1-11.

10. Mgonja S, Schoening A. Postpartum depression screening at well-child appointments: a quality improvement project. J Pediatr Health Care. 2017; 31(2):178-83.

11. Ukatu N, Clare CA, Brulja M. Postpartum depression screening tools: a review. Psychosomatics. 2018;59(3):211-9.

12. Rogathi JJ, Manongi R, Mushi D, Rasch V, Sigalla GN, Gammeltoft T, et al. Postpartum depression among women who have experienced intimate partner violence: a prospective cohort study at Moshi, Tanzania. J Affect Disord. 2017;218:238-45

13. Thein-Nissenbaum J. The postpartum triathlete. Physical Therapy Sport. 2016;21:95-106

14. Keshavarz SA, Mostafavi S-A, Akhondzadeh S, Mohammadi MR, Hosseini S, Eshraghian MR, et al. Omega-3 supplementation effects on body weight and depression among dieter women with co-morbidity of depression and obesity compared with the placebo: a randomized clinical trial. Clin Nutrition ESPEN. 2018;25:37-43.

15. Rogan SC, Payne JL, Meltzer-Brody S. Relationship Between Depressive Mood and Maternal Obesity: Implications for Postpartum Depression. Obesity During Pregnancy in Clinical Practice: Springer; 2014. p. 99-120.

16. Sumithran P, Houlihan C, Shub A, Churilov L, Pritchard N, Price S, et al. How common is substantial weight gain after pregnancy? Obesity Research Clin Practice. 2018;12(2):139-45.

17. Ertel KA, Huang T, Rifas-Shiman SL, Kleinman K, Rich-Edwards J, Oken E, et al. Perinatal weight and risk of prenatal and postpartum depressive symptoms. Annals Epidemiol. 2017:27(11):695-700 e1.

18. LaCoursiere DY, Barrett-Connor E, O'Hara MW, Hutton A, Varner MW. The association between prepregnancy obesity and screening positive for postpartum depression. Bjog-an Int J Obstetrics Gynaecol. 2010;117(8):1011-8.

19. Ruyak SL, Lowe NK, Corwin EJ, Neu M, Boursaw B. Prepregnancy obesity and a biobehavioral predictive model for postpartum depression. Jognn-J Obstetric Gynecol Neonatal Nurs. 2016:45(3):326-38.

20. Ezzeddin N, Jahanihashemi H, Zavoshy R, Noroozi M. The prevalence of postpartum depression and its association with food insecurity among mothers referring to community health centers. Iran J Psychiatry. 2018;13(4):280-7.

21. Azale T, Fekadu A, Medhin G, Hanlon C. Coping strategies of women with postpartum depression symptoms in rural Ethiopia: a cross-sectional community study. Bmc Psychiatry. 2018;18:1-13.

22. Zhao Y, Munro-Kramer ML, Shi S, Wang J, Zhu X. A longitudinal study of perinatal depression among Chinese high-risk pregnant women. Women Birth. 2018:31(6):e395-e402.

23. Bledsoe SE, Rizo CF, Wike TL, Killian-Farrell C, Wessel J, Bellows A-MO, et al. Pregnant adolescent women's perceptions of depression and psychiatric services in the United States. Women Birth. 2017;30(5):e248-e57.

24. Fan Q, Long Q, De Silva V, Gunarathna N, Jayathilaka U, Dabrera T, et al. Prevalence and risk factors for postpartum depression in Sri Lanka: a population-based study. Asian J Psychiatr. 2020;47:101855.

25. Ghaedrahmati M, Kazemi A, Kheirabadi G, Ebrahimi A, Bahrami M Postpartum depression risk factors: a narrative review. J Education Health Promotion. 2017:6:1-24.

26. Chung T-C, Chung $\mathrm{C}-\mathrm{H}$, Peng $\mathrm{H}-\mathrm{J}$, Tsao $\mathrm{C}-\mathrm{H}$, Chien W-C, Sun H-F. An analysis of whether sleep disorder will result in postpartum depression. Oncotarget. 2018;9(38):25304.

27. Chen CM, Kuo SF, Chou YH, Chen HC. Postpartum Taiwanese women: their postpartum depression, social support and health-promoting lifestyle profiles. J Clin Nurs. 2007;16(8):1550-60

28. Chen H-L, Cai J-Y, Zha M-L, Shen W-Q. Prenatal smoking and postpartum depression: a meta-analysis. J Psychosom Obstet Gynecol. 2018:40(2):1-9.

29. dos Santos AM, Benute GRG, dos Santos NO, Nomura RMY, de Lucia MCS Francisco RPV. Presence of eating disorders and its relationship to anxiety and depression in pregnant women. Midwifery. 2017:51:12-5

30. Harris AA. Practical advice for caring for women with eating disorders during the perinatal period. J Midwifery Women's Health. 2010;55(6):579-86.

31. Fuller-Tyszkiewicz M, Broadbent J, Richardson B, Watson B, Klas A, Skouteris $\mathrm{H}$. A network analysis comparison of central determinants of body dissatisfaction among pregnant and non-pregnant women. Body Image. 2020;32:111-20 
32. Köhler R, Lambert C, Biesalski HK. Animal-based food taboos during pregnancy and the postpartum period of southeast Asian women-a review of literature. Food Res Int. 2019;115:480-6.

33. Omar SR, Omar SN. Malaysian heritage food (MHF): a review on its unique food culture, tradition and present lifestyle. Int J Heritage Art Multimedia. 2018;1(3):01-15.

34. Aluş Tokat M, Sancı M, Girgeç S, Kulhan NG, Özcan ÇY. Postpartum education and lifestyle changes for preventing type 2 diabetes in Turkish women with previous gestational diabetes: a retrospective study. Int J Nurs Pract. 2016;22(5):427-35.

35. Nathanson R, Hill B, Skouteris H, Bailey C. Antenatal diet and postpartum depressive symptoms: a prospective study. Midwifery. 2018;62:69-76.

36. Fadzil F, Shamsuddin K, Puteh SEW, Tamil AM, Ahmad S, Hayi NSA, et al. Predictors of postpartum weight retention among urban Malaysian mothers: a prospective cohort study. Obes Res Clin Pract. 2018;12(6):493-9.

37. Tong M, Jin L, Liu J, Li Z, Li H, Zhang L, et al. Association between gestational weight gain and exclusive breast-feeding for the first 6 months postpartum in Chinese women. Public Health Nutr. 2019;22(11):1-7.

38. Fisher SD, Sit DK, Yang A, Ciolino JD, Gollan JK, Wisner KL. Four maternal characteristics determine the 12-month course of chronic severe postpartum depressive symptoms. Depression Anxiety. 2019:36(4):375-83.

39. Moran LJ, Flynn AC, Louise J, Deussen AR, Dodd JM. The effect of a lifestyle intervention on pregnancy and postpartum dietary patterns determined by factor analysis. Obesity. 2017;25(6):1022-32.

40. Huvinen E, Koivusalo SB, Meinilä J, Valkama A, Tiitinen A, Rönö K, et al. Effects of a lifestyle intervention during pregnancy and first postpartum year: findings from the RADIEL study. J Clin Endocrinol Metabolism. 2018; 103(4):1669-77.

41. Okun ML, Mancuso RA, Hobel CJ, Schetter CD, Coussons-Read M. Poor sleep quality increases symptoms of depression and anxiety in postpartum women. J Behav Med. 2018;41(5):703-10.

42. Kay MC, Wasser H, Adair LS, Thompson AL, Siega-Riz AM, Suchindran $\mathrm{CM}$, et al. Consumption of key food groups during the postpartum period in low-income, non-Hispanic black mothers. Appetite. 2017;117: $161-7$.

43. Faria-Schutzer DB, Surita FG, Rodrigues $L$, Turato ER. Eating Behaviors in Postpartum: A Qualitative Study of Women with Obesity. Nutrients. 2018; 10(7)1-11.

44. Nakayama K, Yamaguchi K, Maruyama S, Morimoto K. The relationship of lifestyle factors, personal character, and mental health status of employees of a major Japanese electrical manufacturer. Environ Health Prev Med. 2001; 5(4):144-9.

45. Khajeheian D, Colabi AM, Shah N, Radzi C, Jenatabadi HS. Effect of Social Media on Child Obesity: Application of Structural Equation Modeling with the Taguchi Method. Int J Environ Res Public Health. 2018;15(7):1-22.

46. Kroller $K$, Warschburger $P$. Maternal feeding strategies and child's food intake: considering weight and demographic influences using structural equation modeling. Int J Behav Nutr Phys Act. 2009;6:1-9.

47. Radzi WM, Jasimah CW, Salarzadeh Jenatabadi H, Alanzi AR, Mokhtar MI, Mamat MZ, et al. Analysis of obesity among Malaysian University students: a combination study with the application of Bayesian structural equation Modelling and Pearson correlation. Int J Environ Res Public Health. 2019, 16(3):492.

48. Orgnization WH. World Health Organization. http://www.who.int/newsroom/fact-sheets/detail/obesity-and-overweight. Accessed 23 Oct 2018.

49. Leigh $L$, Byles JE, Jagger $C$. BMI and healthy life expectancy in old and very old women. Br J Nutr. 2016;116(4):692-9.

50. Di Florio A, Putnam K, Altemus M, Apter G, Bergink V, Bilszta J, et al. The impact of education, country, race and ethnicity on the self-report of postpartum depression using the Edinburgh postnatal depression scale. Psychol Med. 2017:47(5):787-99.

51. Kubota $C$, Inada T, Nakamura $Y$, Shiino T, Ando M, Aleksic B, et al. Stable factor structure of the Edinburgh postnatal depression scale during the whole peripartum period: results from a Japanese prospective cohort study. Sci Rep. 2018:8:1-7.

52. Bozzatello P, Brignolo E, De Grandi E, Bellino S. Supplementation with omega-3 fatty acids in psychiatric disorders: a review of literature data. J Clin Med. 2016;5(8):67.

53. Koh Y, Lee A, Chan C, Fong D, Lee C, Leung K, et al. Survey on examining prevalence of paternal anxiety and its risk factors in perinatal period in Hong Kong: a longitudinal study. BMC Public Health. 2015;15(1):1131.
54. Mohamad Yusuff AS, Tang L, Binns CW, Lee AH. Prevalence of antenatal depressive symptoms among women in Sabah, Malaysia. J Matern Feta Neonatal Med. 2016;29(7):1170-4.

55. Rashid A, Mohd R. Poor social support as a risk factor for antenatal depressive symptoms among women attending public antennal clinics in Penang, Malaysia. Reproductive Health. 2017;14(1):144.

56. Yawn BP, Pace W, Wollan PC, Bertram S, Kurland M, Graham D, et al. Concordance of Edinburgh postnatal depression scale (EPDS) and patient health questionnaire (PHQ-9) to assess increased risk of depression among postpartum women. J Am Board Family Med. 2009; 22(5):483-91.

57. Shimamoto K, Gipson JD. Examining the mechanisms by which women's status and empowerment affect skilled birth attendant use in Senegal: a structural equation modeling approach. Bmc Pregnancy and Childbirth. 2017;17(2):341.

58. Kananura RM, Wamala R, Ekirapa-Kiracho E, Tetui M, Kiwanuka SN, Waiswa P, et al. A structural equation analysis on the relationship between maternal health services utilization and newborn health outcomes: a cross-sectional study in eastern Uganda. Bmc Pregnancy Childbirth. 2017;17(1):98.

59. Gefen D, Straub D, Boudreau M-C. Structural equation modeling and regression: guidelines for research practice. Commun Assoc Inf Syst. 2000;4(1):7.

60. Jeon J. The strengths and limitations of the statistical modeling of complex social phenomenon: focusing on SEM, path analysis, or multiple regression models. Int J Social Behavioral Educ Econ Business Industrial Eng. 2015;9(5): 1559-67.

61. Hair J, Black W, Babin B, Anderson R. Multivariate data analysis: Pearson new international edition. New Jersey: Pearson/Prentice Hall; 2014

62. Fornell C, Larcker DF. Evaluating structural equation models with unobservable variables and measurement error. J Mark Res. 1981;18(1): $39-50$.

63. Ahmad A, Zulaily N, Shahril MR, Abdullah EFHS, Ahmed A. Association between socioeconomic status and obesity among 12-year-old Malaysian adolescents. PloS one. 2018;13(7):1-11.

64. Raza L, Ali TM, Hasnain A. Comparison of dietary practices and body mass index among educated housewives and working women in Karachi. J Ayub Medical College Abbottabad. 2017:29(2):293-7.

65. Zagorsky $\mathrm{J}$, Smith PK. The association between socioeconomic status and adult fast-food consumption in the US. Economics Human Biol. 2017:27:12-25.

66. Fryar CD, Hughes JP, Herrick KA, Ahluwalia N. Fast food consumption among adults in the United States, 2013-2016; 2018.

67. Hidaka BH, Hester CM, Bridges KM, Daley CM, Greiner KA. Fast food consumption is associated with higher education in women, but not men, among older adults in urban safety-net clinics: a cross-sectional survey. Prev Med Rep. 2018:12:148-51.

68. Garza KB, Ding M, Owensby JK, Zizza CA. Impulsivity and fast-food consumption: a cross-sectional study among working adults. J Acad Nutr Diet. 2016;116(1):61-8.

69. Kim E, Cho I, Kim EJ. Structural equation model of smartphone addiction based on adult attachment theory: mediating effects of loneliness and depression. Asian Nurs Res. 2017;11(2):92-7.

70. Berk M, Sarris J, Coulson CE, Jacka FN. Lifestyle management of unipolar depression. Acta Psychiatr Scand. 2013;127:38-54.

71. Paans NP, Gibson-Smith D, Bot M, van Strien $T$, Brouwer IA, Visser $M$, et al. Depression and eating styles are independently associated with dietary intake. Appetite. 2019:134:103-10.

72. Ali N, Abdullah MA. The food consumption and eating behaviour of Malaysian urbanites: Issues and concerns. Geografia Malays J Soc Space. 2017:8(6):157-65.

73. Nagl M, Linde $K$, Stepan $H$, Kersting A. Obesity and anxiety during pregnancy and postpartum: a systematic review. J Affect Disord. 2015;186: 293-305.

74. Abdollahi F, Agajani-Delavar M, Zarghami M, Lye MS. Postpartum Mental Health in First-Time Mothers: A Cohort Study. Iranian J Psychiatry Behavioral Sciences. 2016:10(1):1-7.

75. Bhusal BR, Bhandari N, Chapagai M, Gavidia T. Validating the Edinburgh postnatal depression scale as a screening tool for postpartum depression in Kathmandu, Nepal. Int J Ment Heal Syst. 2016;10:1-7.

76. Quezada AD, Macías-Waldman N, Salmerón J, Swigart T, Gallegos-Carrillo K. Physical activity and calorie intake mediate the relationship from depression to body fat mass among female Mexican health workers. Int J Behav Nutr Phys Act. 2017;14(1):160. 
77. Kishida M, Elavsky S. An intensive longitudinal examination of daily physical activity and sleep in midlife women. Sleep Health. 2016;2(1):42-8.

78. Staiano AE, Marker AM, Martin CK, Katzmarzyk PT. Physical activity, mental health, and weight gain in a longitudinal observational cohort of nonobese young adults. Obesity. 2016;24(9):1969-75.

79. Lincoln KD. Social stress, obesity, and depression among women: clarifying the role of physical activity. Ethnicity Health. 2019;24(6):662-78.

80. Barker ED, Kirkham N, Ng J, Jensen SK. Prenatal maternal depression symptoms and nutrition, and child cognitive function. Br J Psychiatry. 2013; 203(6):417-21.

81. Jacka FN, Berk M. Depression, diet and exercise. Med J Aust. 2013;199(6):21-3.

82. Pina-Camacho L, Jensen S, Gaysina D, Barker E. Maternal depression symptoms, unhealthy diet and child emotional-behavioural dysregulation. Psychol Med. 2015;45(9):1851-60.

83. Privitera GJ, King-Shepard QW, Cuifolo KN, Doraiswamy PM. Differential food intake and food choice by depression and body mass index levels following a mood manipulation in a buffet-style setting. J Health Psychol. 2016; 1359105316650508:1-11.

84. McVay MA, Yancy WS, Bennett GG, Jung S-H, Voils Cl. Perceived barriers and facilitators of initiation of behavioral weight loss interventions among adults with obesity: a qualitative study. BMC Public Health. 2018;18(1):854.

85. Beleigoli AM, de Andrade AQ, Diniz MdFH, Alvares RS, Ribeiro AL. Online platform for healthy weight loss in adults with overweight and obesity-the "POEmaS" project: a randomized controlled trial. BMC Public Health. 2018; 18(1):945.

86. Noh J-W, Kwon YD, Yang Y, Cheon J, Kim J. Relationship between body image and weight status in east Asian countries: comparison between South Korea and Taiwan. BMC Public Health. 2018;18(1):814.

87. Miller YD, Trost SG, Brown WJ. Mediators of physical activity behavior change among women with young children. Am J Prev Med. 2002;23(2):98-103.

88. Groth SW, David T. New mothers' views of weight and exercise. MCN Am J Maternal Child Nurs. 2008;33(6):364.

89. Dlugonski D, Motl RW. Marital status and motherhood: implications for physical activity. Women Health. 2013;53(2):203-15.

90. Purdue-Smithe AC, Whitcomb BW, Manson JE, Hankinson SE, Rosner BA, Troy LM, et al. A prospective study of dairy-food intake and early menopause. Am J Epidemiol. 2019:188(1):188-96.

91. Grasso AC, Olthof MR, van Dooren C, Roca M, Gili M, Visser M, et al. Effect of food-related behavioral activation therapy on food intake and the environmental impact of the diet: results from the MooDFOOD prevention trial. Eur J Nutr. 2019:1-13.

\section{Publisher's Note}

Springer Nature remains neutral with regard to jurisdictional claims in published maps and institutional affiliations.

Ready to submit your research? Choose BMC and benefit from:

- fast, convenient online submission

- thorough peer review by experienced researchers in your field

- rapid publication on acceptance

- support for research data, including large and complex data types

- gold Open Access which fosters wider collaboration and increased citations

- maximum visibility for your research: over $100 \mathrm{M}$ website views per year

At $\mathrm{BMC}$, research is always in progress.

Learn more biomedcentral.com/submissions 